\title{
The Wire Drawing Mechanics of Near-Equiatomic NiTi SMA
}

\author{
André da Silva Antunes ${ }^{\circledR} \mathbb{D}^{-}$, Osmar de Sousa Santos ${ }^{a}$, Leonardo Kenji Fudo Naito ${ }^{a}$, Odair Dona Rigo ${ }^{b}$,
}

\author{
Jorge Otubo ${ }^{a} *$ (D) \\ aITA Shape Memory Alloy Research and Technology Group - ITASMART, Instituto Tecnológico de \\ Aeronáutica - ITA, 12.228-900, São José dos Campos, SP, Brasil \\ ${ }^{b}$ Centro Tecnológico da Marinha - CTM, São Paulo, SP, Brasil
}

Received: October 18, 2017; Revised: January 24, 2018; Accepted: February 27, 2018

\begin{abstract}
The wire drawing mechanic of Ti-49.82Ni (at. \%) Shape Memory Alloy (SMA) was investigated through the true stress-strain curves and drawing stresses. The tensile tested solution treated wire presented a four steps elongation at temperatures below the austenite finish temperature $\left(\mathrm{A}_{\mathrm{F}}\right)$, and a conventional one-step behavior above the martensite deformation temperature $\left(\mathrm{M}_{\mathrm{D}}\right)$. The tensile yield stress for the formation of detwinned martensite (DTM) or stress-induced martensite (SIM) increased as the testing temperature increased; however, for larger deformation, the behavior reversed. The efficiency of drawing work, which is the ratio of uniform work to total work, increased from $10 \%$ for $0.07 \mathrm{~mm}^{2} . \mathrm{mm}^{-2}$ area reduction at $25^{\circ} \mathrm{C}$ to $50 \%$ for $0.21 \mathrm{~mm}^{2} . \mathrm{mm}^{-2}$ at $110{ }^{\circ} \mathrm{C}$. Therefore, wire drawing temperature and area reduction should be combined to increase the efficiency, taking into account the desired properties with reasonable workability. Furthermore, transformation work should be considered on wire drawing shape memory alloys as phase transformation occurs in temperatures below $M_{D}$.
\end{abstract}

Keywords: NiTi, Shape Memory Alloys, Wire Drawing, Uniform Work, Transformation Work.

\section{Introduction}

The NiTi SMAs are a special class of materials with properties such as shape memory effect (SME) and/or superelasticity $(\mathrm{SE})^{1,2}$. Those properties provide the capability of recovering from the high amount of strain upon heating (SME) or upon mechanical load relieve $(\mathrm{SE})^{2,3}$. Those non-conventional properties are useful in applications such as microgripper ${ }^{4}$, actuators, microactuators ${ }^{5}$, stents, surgical implants, dental arc-wire ${ }^{6,7}$ and endodontic files, as well as automotive, naval, and aerospace technologies ${ }^{6}$.

NiTi shape memory alloys are produced by $\mathrm{EBM}^{8}$ or by VIM, and then thermomechanically transformed into bars and wires. Thermomechanical processing influences the shape memory and/or superelasticity properties of NiTi alloys $^{2,9-11}$. Because most of the applications of NiTi SMAs are in wire form, the end stage of the fabrication process is frequently done by wire drawing. Therefore, understanding the drawing mechanics is an important issue to broaden applications of NiTi SMAs.

In wire drawing of conventional metals and alloys, the total drawing work per unit volume is given by the uniform work, redundant work, and frictional work. The only work that effectively contributes to deform the wire is the uniform work, while redundant work is the energy spent to shear deform parallel to die surface to compensate for the difference in mass flow gradient from the wire axis to surface, and frictional work is the energy spent due to friction between die surface and wire surface. The total work is equal to the drawing stress, and the uniform work is the area under the true stress-strain curve for a respective strain or area reduction ${ }^{12}$.

The deformation under tensile or compressive load of conventional metallic materials develops in two steps: initially the elastic deformation and then the plastic deformation. In contrast, NiTi SMAs have non-conventional mechanical behavior at temperature below $\mathrm{M}_{\mathrm{D}}$ (maximum temperature at which the martensite phase can be stress induced $)^{2,13}$, deforming in four steps: initially the elastic deformation of pre-existing phase (martensite (M), austenite (A) or a mix of $\mathrm{M}$ and $\mathrm{A}$ ); next a pseudoplastic deformation associated with the martensite variants reorientation or detwinned martensite (DTM) (if the previous phase is M) or the formation of stress-induced martensite (SIM) (if the previous phase is A); then the elastic deformation of martensite (DTM or SIM); and finally the plastic deformation ${ }^{10}$. Therefore, it is reasonable to expect that, at least in the first drawing pass of work hardening, NiTi SMAs will have distinct drawing mechanics, due to the possible occurrence of the transformation of M to DMT and/or phase transformation from A to SIM during mechanical deformation compared to conventional metallic materials. 
The literature related to the wire drawing of SMAs is very scarce and no information related to phase transformation occurring during wire drawing has been reported. Wu et al. ${ }^{14}$ concluded that a multi-pass drawing must be performed at drawing temperatures around martensite start temperature $\left(\mathrm{M}_{\mathrm{S}}\right)$. The objective of this work is to investigate the influences of previous (pre-existent) phase on the wire drawing of near-equiatomic NiTi SMA. It is industrially important to optimize the wire drawing setup and then reduce the energy consumption.

\section{Experimental Procedure}

The starting Ti-49.82Ni (at.\%) ingot of $50 \mathrm{~mm}$ in diameter produced by vacuum induction melting (VIM) (hereafter-called NiTi) was hot rolled down to $15 \mathrm{~mm}$ diameter and then hot rotary swaged to $3.40 \mathrm{~mm}$ diameter using a 4-Dies and 2-Dies rotary swaging machines. The rolling and swaging temperature were about $850{ }^{\circ} \mathrm{C}$ with a soaking time of $15 \mathrm{~min}$. Next, using a 5 HP single bull block wire drawing machine, the bar was cold drawn into wires with three distinct diameters: $2.080,2.163$, and 2.251 $\mathrm{mm}$, using $8^{\circ}$ half-angle tungsten carbide dies lubricated with $\mathrm{MoS}_{2}$-based lubricant. The area reduction per drawing pass was $15 \%\left(0.15 \mathrm{~mm}^{2} . \mathrm{mm}^{-2}\right)$ at a drawing speed of $\sim 760$ $\mathrm{mm} . \mathrm{s}^{-1}$. An intermediate annealing at $750{ }^{\circ} \mathrm{C}$ for $15 \mathrm{~min}$ was applied for every single wire drawing pass. At final diameters of $2.080,2.163$, and $2.251 \mathrm{~mm}$, the wires were solution treated at $850{ }^{\circ} \mathrm{C}$ per $30 \mathrm{~min}$ in air, and then saved for the next wire drawing experiment.

The martensitic transformation temperatures were determined using a differential scanning calorimeter (DSC). The heating and cooling rate was $10^{\circ} \mathrm{C} / \mathrm{min}$ according to ASTM Standard F 2004-0 $5^{15}$. The following parameters were recorded: for cooling, the $\mathrm{M}_{\mathrm{S}}, \mathrm{M}_{\mathrm{P}}$, and $\mathrm{M}_{\mathrm{F}}$ are, respectively, the start, peak, and finish of direct martensitic transformation temperatures; and for heating, the $\mathrm{A}_{\mathrm{S}}, \mathrm{A}_{\mathrm{P}}$, and $\mathrm{A}_{\mathrm{F}}$, which are, respectively, the start, peak, and finish of reverse martensitic transformation temperatures. The DSC sample was taken from a solution treated $2.080 \mathrm{~mm}$ diameter.

To calculate the uniform work (per unit volume), which is the area under the true stress-strain curve ${ }^{12}$, part of the wire, saved at $2.080 \mathrm{~mm}$ in diameter in a solution treated condition, was divided into five pieces. Then each piece was tensile tested in one respective temperature of $25,70,75,80$, and $110^{\circ} \mathrm{C}$, using an Instron 5500R tensile testing machine coupled with an Instron 3119 environmental chamber.

To record the total drawing work (per unit volume), the drawing test was carried out inside the environmental chamber with a die-holder using an Instron 5500R tensile testing machine as shown in Figure $1 \mathrm{a}$ ) and b). In this test, the load was measured at different drawing conditions as follow: the wires at diameters of 2.080, 2.163, and 2.251 $\mathrm{mm}$ from the previous stage were all drawn in a single pass down to $2.004 \mathrm{~mm}$ in diameter resulting respectively in 7,14 , and $21 \%$ of the area reduction (or $0.07 ; 0.14$, and $0.21 \mathrm{~mm}^{2} \cdot \mathrm{mm}^{-2}$ area reduction) at temperatures of 25,70 , 75,80 , and $110^{\circ} \mathrm{C}$. The total work or drawing stress is the load force necessary to pull the wire downstream from the die divided by the final area experimentally obtained as presented in Figure 1. The carbide die was lubricated with $\mathrm{MoS}_{2}$ based lubricant and the drawing speed was $300 \mathrm{~mm} / \mathrm{s}$. The included die angle $2 \alpha$ was adjusted to keep the $\Delta$ factor about 2 to avoid excessive non-uniform work ( $\Delta$ factor is the ratio of the average diameter of deformation zone to the length of deformation zone $)^{12}$. The above experiments made it possible to calculate the drawing works at different temperatures by determining the drawing loads.
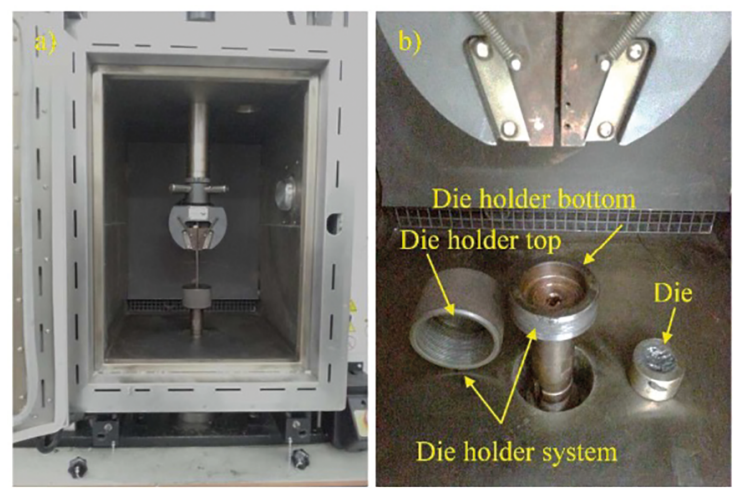

Figure 1. Wire drawing test: a) overall view of wire drawing apparatus inside the environmental chamber. b) details of the die holder.

\section{Results and Discussions}

Figure 2 shows the transformation behavior of the solution treated $2.080 \mathrm{~mm}$ in diameter wire. The direct and reverse martensitic transformations occur at just one step, B19' (martensite) $\leftrightarrow$ B2 (austenite). The DSC results are summarized in Table 1. The wires are in the martensitic state at room temperature $\left(25^{\circ} \mathrm{C}\right)$, in a mixed state $(\mathrm{M}+$ A) at 70 and $75^{\circ} \mathrm{C}$, and in the austenitic state at 80 and 110 ${ }^{\circ} \mathrm{C}$, which is corroborated by tensile and wire drawing tests.

Figure 3 shows the true stress-strain curves of solution treated $2.080 \mathrm{~mm}$ in diameter wire, tensile tested at 25, 70, 75,80 , and $110^{\circ} \mathrm{C}$. At 25 and $70^{\circ} \mathrm{C}$, the wires exhibit a stress plateau (critical stress) after the first yield stress and present the characteristic SMA pseudoplastic deformation ${ }^{16}$. At $25^{\circ} \mathrm{C}$, the wire is in the martensitic state, according to Table 1, and show two well-defined yield stresses, one at $\sim 160 \mathrm{MPa}$ and the other at $\sim 600 \mathrm{MPa}$. The first yield stress corresponds to the pseudoplastic deformation (beginning of detwining or reorientation of pre-existing martensite variants), and the second yield stress, to the beginning of conventional plastic deformation of detwinned martensite 
Table 1. Direct and reverse martensitic transformation temperatures of the solution treated $2.080 \mathrm{~mm}$ in diameter wire.

\begin{tabular}{ccccccc}
\hline $\mathrm{M}_{\mathrm{S}}\left({ }^{\circ} \mathrm{C}\right)$ & $\mathrm{M}_{\mathrm{P}}\left({ }^{\circ} \mathrm{C}\right)$ & $\mathrm{M}_{\mathrm{F}}\left({ }^{\circ} \mathrm{C}\right)$ & $\mathrm{A}_{\mathrm{S}}\left({ }^{\circ} \mathrm{C}\right)$ & $\mathrm{A}_{\mathrm{P}}\left({ }^{\circ} \mathrm{C}\right)$ & $\mathrm{A}_{\mathrm{F}}\left({ }^{\circ} \mathrm{C}\right)$ & $\mathrm{M}_{\mathrm{D}}{ }^{*}\left({ }^{\circ} \mathrm{C}\right)$ \\
\hline 46.0 & 36.7 & 26.0 & 60.6 & 74.8 & 79.0 & Between 80 and 110 \\
\hline
\end{tabular}

* The MD value was estimated by the shape of curves from tensile test presented in Figure 3.

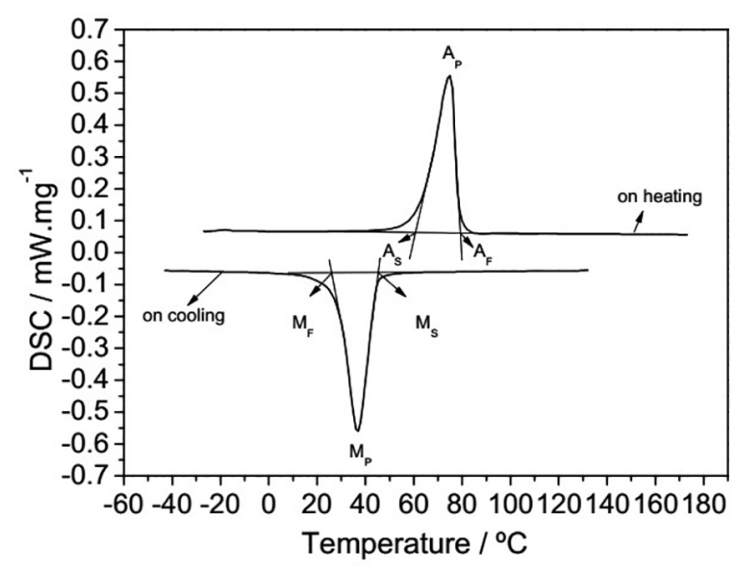

Figure 2. DSC measurements of transformation behavior of the solution treated $2.080 \mathrm{~mm}$ in diameter wire.

(DTM). At $70{ }^{\circ} \mathrm{C}$, the wire has a mixed crystallographic state $(\mathrm{M}+\mathrm{A})$, where the temperature is between $\mathrm{A}_{\mathrm{s}}(60.6$ $\left.{ }^{\circ} \mathrm{C}\right)$ and $\mathrm{A}_{\mathrm{F}}\left(79.0^{\circ} \mathrm{C}\right)$. Although the tensile curve profile at $70{ }^{\circ} \mathrm{C}$ was similar to the one at $25^{\circ} \mathrm{C}$, the first yield stress is $25 \%$ higher $(200 \mathrm{MPa})$ and the second yield stress is $10 \%$ lower $(\sim 540 \mathrm{MPa})$ than that in the $25^{\circ} \mathrm{C}$ test. The first yield stress is related to the beginning of the detwinning of thermal martensite and the beginning of the stress-induced martensite (SIM). The second yield stress is the beginning of plastic deformation of the martensite (DTM + SIM), as before at $25^{\circ} \mathrm{C}$. At 75 and $80^{\circ} \mathrm{C}$, the characteristic double yield stress almost disappears taking into account that $\mathrm{A}_{\mathrm{F}}$ is $79.0^{\circ} \mathrm{C}$. In this case, the yield stress is the stress necessary to stress induce the martensite which is higher, the higher the tensile testing temperature, indicating that the austenite is a stable phase $\mathrm{e}^{10,16}$. At $110^{\circ} \mathrm{C}$, the tensile behavior tends to be similar to a conventional metallic material presenting only one yield stress, and no SIM is seen, which indicates that the wire should be above $M_{D}\left(M_{D}\right.$ is the highest temperature to $\left.\mathrm{SIM}^{2,13}\right)$. Still from Figure 3, disregarding the type of deformation, the specific NiTi mechanical behavior induces the following conclusions: the $25{ }^{\circ} \mathrm{C}$ curve illustrates that up to about $0.07 \mathrm{~mm}^{2} . \mathrm{mm}^{-2}$ strain, the wire behaves like a soft metallic material with low yield stress (e. g. $\sim 160$ $\mathrm{MPa}$ at $25^{\circ} \mathrm{C}$ ) and low work-hardening. For higher strains, the wire behaves like a hard-metallic material with a high yield stress of about $600 \mathrm{MPa}$, which surpasses mechanical resistance of the higher testing temperature and has higher work-hardening.

The upper plateau strength (UPS), also known as critical stress, is the stress at $3 \%$ of strain during loading test ${ }^{13}$. The

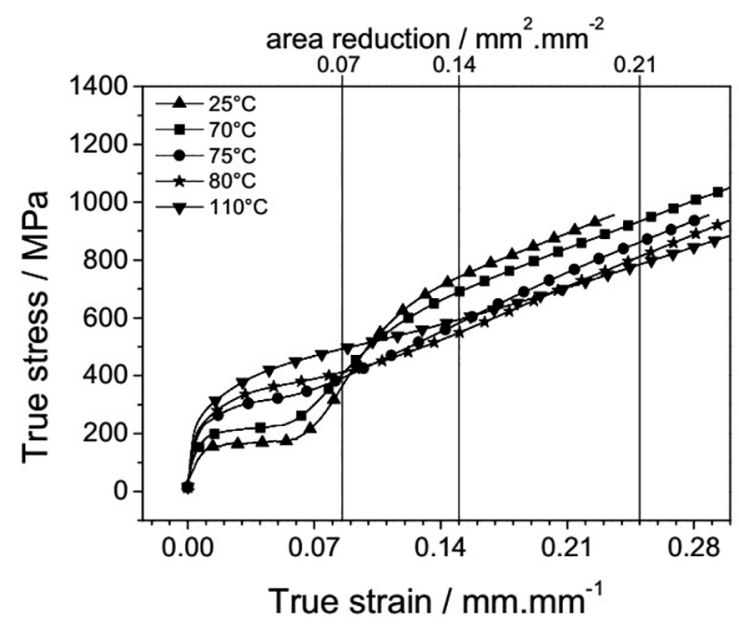

Figure 3. True stress-strain curves of solution treated $2.080 \mathrm{~mm}$ wire tensile tested at $25,70,75,80$, and $110^{\circ} \mathrm{C}$.

literature shows that the UPS, of a near equiatomic NiTi shape memory alloy, increases monotonically from $\sim 140$ to $\sim 325 \mathrm{MPa}$ when the test temperature increases from $\mathrm{A}_{\mathrm{S}}$ to $\mathrm{A}_{\mathrm{F}}{ }^{11}$. As can be seen in Figure 3, the UPS increased from 213 to $331 \mathrm{MPa}$, when the temperature increased from $70^{\circ} \mathrm{C}$ (close to $A_{\mathrm{S}}$ ) to $80^{\circ} \mathrm{C}$ (close to $A_{F}$ ). It is expected that this mechanical behavior will influence the wire drawing process.

The above results are very important in terms of practical wire drawing insofar as the area reduction involved is usually higher than $0.10 \mathrm{~mm}^{2} \cdot \mathrm{mm}^{-2}$. For a complete understanding of wire drawing work, the uniform drawing work and total drawing work should be analyzed.

Considering that the area under the true stress-strain curve corresponds to uniform work, it is expected that the wire drawing will be influenced by this non-conventional mechanical behavior originated by pseudoplastic deformation. As two kinds of deformations exist, the plastic and the pseudoplastic, the uniform work must be distinguished by naming one as "plastic uniform work", and other as "pseudoplastic uniform work", and the total uniform work or just the uniform work is the sum of them. Figure 4 shows the uniform work, calculated from the true stress-strain curves of Figure 3, limited to the left of vertical lines at $0.075,0.15$, and $0.24 \mathrm{~mm} . \mathrm{mm}^{-1}$ of true strain that correspond to $0.07,0.14$, and $0.21 \mathrm{~mm}^{2} \cdot \mathrm{mm}^{-2}$ of area reduction in wire drawing, as a function of the tensile testing temperature. Comparing the three deformations shows that the pseudoplastic uniform work, for a $0.07 \mathrm{~mm}^{2} . \mathrm{mm}^{-2}$ area reduction, increases as the temperature increases and is more sensitive at temperatures between 70 and $80^{\circ} \mathrm{C}$, that is between $\mathrm{A}_{\mathrm{S}}$ and $\mathrm{A}_{\mathrm{F}}$. At $110^{\circ} \mathrm{C}$, the plastic uniform work 


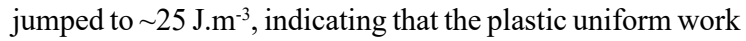
is higher than that of the pseudoplastic uniform work. The uniform drawing work for a $0.14 \mathrm{~mm}^{2} . \mathrm{mm}^{-2}$ area reduction, also presents similar behavior as for $0.07 \mathrm{~mm}^{2} . \mathrm{mm}^{-2}$, but the positive steepness as the temperature increases is lower, noting that, in this case, the plastic deformation of DTM and SIM is occurring due to higher strain. The values are respectively $\sim 45 \mathrm{~J} \mathrm{~m}^{-3}$ at $25^{\circ} \mathrm{C}$ and $\sim 65 \mathrm{~J}^{-m^{-3}}$ at $110^{\circ} \mathrm{C}$. For a $0.21 \mathrm{~mm}^{2} . \mathrm{mm}^{-2}$ area reduction, the uniform work is constant up to $70^{\circ} \mathrm{C}$ and then decreases for deformation at a higher temperature of 75 and $80^{\circ} \mathrm{C}$, then slightly increases at 110 ${ }^{\circ} \mathrm{C}$, with the extremes values of $\sim 105 \mathrm{~J}^{-3}{ }^{-3}$. The uniform work, in this case, corresponds to the conventional plastic deformation of the austenite phase. Figure 5 presents the total work as a function of temperature for $0.07,0.14$ and 0.21 $\mathrm{mm}^{2} . \mathrm{mm}^{-2}$ area reductions. Remember that the total work corresponds to the sum of uniform work, redundant work, and friction work; the last two terms do not contribute to effective deformation and should be minimized.

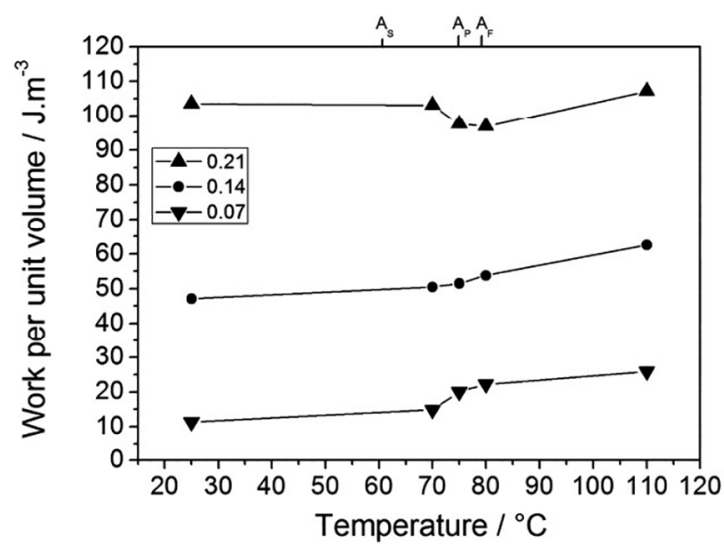

Figure 4. The uniform work calculated from the tensile testing of solution treated $2.080 \mathrm{~mm}$ diameter wire as a function of temperature for $0.07,0.14$, and $0.21 \mathrm{~mm}^{2} . \mathrm{mm}^{-2}$ area reduction.

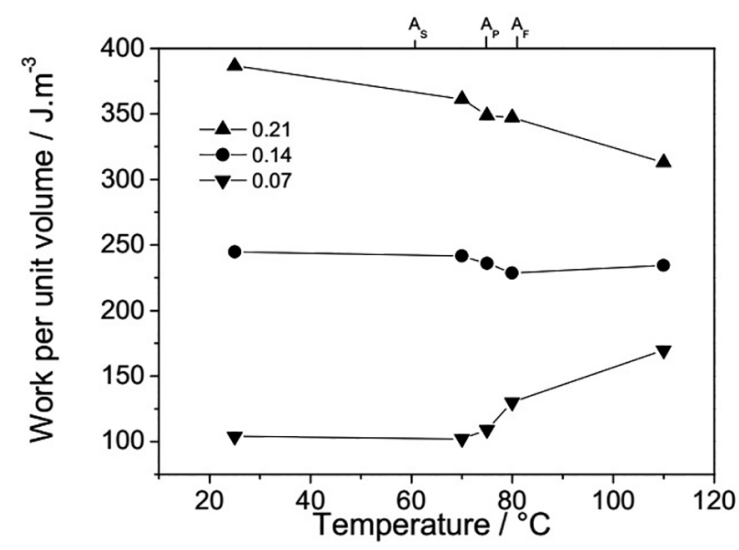

Figure 5. The total drawing work as a function of drawing temperature for the solution treated $2.080 \mathrm{~mm}$ diameter wire, drawn in a single pass of $0.07,0.14$, and $0.21 \mathrm{~mm}^{2} . \mathrm{mm}^{-2}$ area reduction.
As shown in Figure 5, for a $0.07 \mathrm{~mm}^{2} . \mathrm{mm}^{-2}$ area reduction, the total work is almost constant up to $70{ }^{\circ} \mathrm{C}\left(\sim 100 \mathrm{~J} . \mathrm{m}^{-3}\right)$, and then increases steeply from 70 to $80^{\circ} \mathrm{C}$ and then to $\sim 175$ $\mathrm{J} . \mathrm{m}^{-3}$ at $110{ }^{\circ} \mathrm{C}$, that is, a $\sim 75 \%$ increase closely following the behavior of uniform work. The pseudoplastic uniform work at $25^{\circ} \mathrm{C}$ is about $10 \%$ and the plastic uniform work is about $14 \%$ at $110^{\circ} \mathrm{C}$ of total work. Therefore, for a low area reduction, the efficiency of drawing work (i.e. the ratio of uniform work to total work) is low and most of the energy is spent as friction work, as the redundant work is supposed to be very low due to the low geometric factor, $\Delta$, of $2^{12}$. For $0.14 \mathrm{~mm}^{2} . \mathrm{mm}^{-2}$ area reduction, the total work is practically constant at $\sim 250{\mathrm{~J} . \mathrm{m}^{-3}}^{-3}$, and in this case, the uniform work corresponds to $20 \%$ at $25{ }^{\circ} \mathrm{C}$ and $26 \%$ at $110{ }^{\circ} \mathrm{C}$ of the total work, improving the drawing efficiency compared to 0.07 $\mathrm{mm}^{2} \cdot \mathrm{mm}^{-2}$ area reduction. The highest degree of deformation, $0.21 \mathrm{~mm}^{2} \cdot \mathrm{mm}^{-2}$ of area reduction, present the best results in terms of total work, and it steeply decreases from $\sim 380$ $\mathrm{J} . \mathrm{m}^{-3}$ at $25{ }^{\circ} \mathrm{C}$ to $\sim 310 \mathrm{~J} . \mathrm{m}^{-3}$ at $110{ }^{\circ} \mathrm{C}$. The uniform work corresponded to $27 \%$ and $50 \%$ of total work in those extremes. The above analyses took into account only the wire drawing temperature and area reduction per drawing pass keeping constant other die parameters such as $\Delta$ factor, drawing angle, and lubricant. The manipulation of those parameters should optimize the uniform work, minimizing the redundant work and the frictional work.

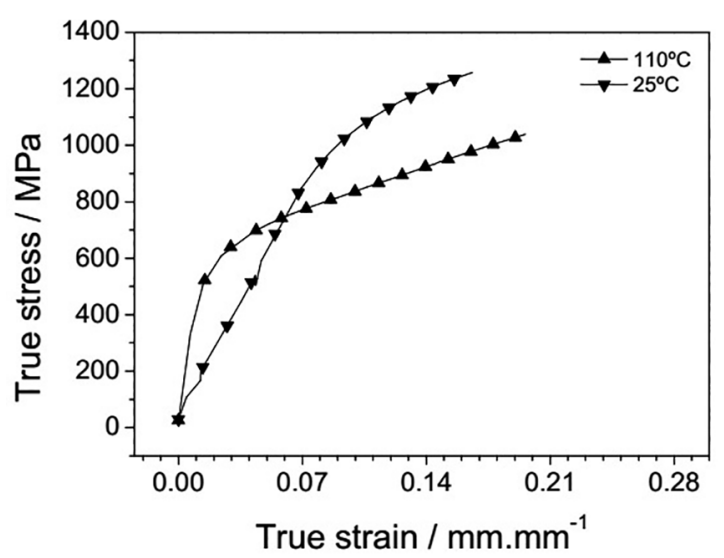

Figure 6. True stress-strain curves at $25^{\circ} \mathrm{C}$ for the wire drawn at 25 and $110^{\circ} \mathrm{C}$ with $0.21 \mathrm{~mm}^{2} \cdot \mathrm{mm}^{-2}$ area reduction.

Figure 6 shows the results of the tensile test at $25{ }^{\circ} \mathrm{C}$ for the wires drawn at 25 and $110{ }^{\circ} \mathrm{C}$ with $0.21 \mathrm{~mm}^{2} \cdot \mathrm{mm}^{-2}$ area reduction. This resulted in two drawing products: the work-hardened martensite wire drawn at $25{ }^{\circ} \mathrm{C}$ and the work-hardened austenite wire drawn at $110^{\circ} \mathrm{C}$, above $\mathrm{M}_{\mathrm{D}}$, therefore no SIM existed. The wire drawn at $25^{\circ} \mathrm{C}$ presented higher tensile stress than that at $110^{\circ} \mathrm{C}$. This would reflect in higher uniform work if a new drawing step is to be carried out. Therefore, the wire should be drawn above $M_{D}$. 
Summarizing, the above results indicate that, for wire drawing with low area reduction, it is much easier to wire draw at low temperature where the martensite state prevails, which corroborates with $\mathrm{Wu}^{14}$. However, for higher area reduction, as is normal of wire drawing, it is more efficient to wire draw in high temperatures, preferentially above $M_{D}$, where the total drawing work and tensile stress of the product are lower. Nevertheless, as shown in earlier work ${ }^{17}$, even for wire drawing at low temperature $\left(25^{\circ} \mathrm{C}\right)$, which is usually done in industrial scale, area reduction as high as $56 \%$ with $15 \%$ area reduction per pass can be obtained.

\section{Conclusion}

The NiTi wire presented a well-known four-step tensile profile at temperatures below $\mathrm{A}_{\mathrm{s}}$ : an elastic deformation of the previous phase; a transformation stress plateau after the first yield stress; an elastic deformation of the new transformed phase; and finally, the second yield stress corresponding to the beginning of conventional plastic deformation. Those characteristics disappear as the temperature approaches $A_{F}$, and above $M_{D}$, the mechanical behavior is similar to a conventional material.

The results of uniform work and total work indicate that the efficiency of wire drawing increases as the area reduction and drawing temperature increases. The contributions of uniform work for $0.07 \mathrm{~mm}^{2} . \mathrm{mm}^{-2}$ area reduction are about 10 and $14 \%$ of total work, respectively, for 25 and $110^{\circ} \mathrm{C}$, while for $0.21 \mathrm{~mm}^{2} \cdot \mathrm{mm}^{-2}$ area reduction are 27 and $50 \%$ of total work for the same range of temperature.

Two drawing products can be obtained varying the drawing temperature: work-hardened martensite (below $\mathrm{M}_{\mathrm{D}}$ ) and work-hardened austenite (above $\mathrm{M}_{\mathrm{D}}$ ).

It is recommended that the wire be drawn at an elevated temperature associated with high area reduction in order to increase the ratio between uniform work and total work, taking into account the desired properties associated to reasonable workability.

Compared to conventional wire drawing, pseudoplastic uniform work should be considered on wire drawing shape memory alloys to distinguish from the plastic uniform work. Studies are underway to incorporate the pseudoplastic uniform work into the total drawing work on wire drawing SMAs.

The results from the wires with final diameters of about $2 \mathrm{~mm}$ can be extrapolated for larger and smaller diameters provided that a specific included die angle $2 \alpha$ can be manufactured.

\section{Acknowledgements}

The authors wish to thank FAPESP, CAPES, CNPq, FINEP, Multialloy Metais Especiais Ltda, and Villares Metals SA for supporting the ITASMART (ITA Shape Memory Alloy Research and Technology) Group.

\section{References}

1. Otsuka K, Wayman CM. Shape Memory Materials. $1^{\text {st }}$ ed. Cambridge University Press; 1998. 300 p.

2. Miyazaki S, Otsuka K. Development of Shape Memory Alloys. ISIJ International. 1989;29(5):353-377.

3. Otsuka K, Ren X. Physical metallurgy of Ti-Ni-based shape memory alloys. Progress in Materials Science. 2005;50(5):511678.

4. Kohl M, Just E, Pfleging W, Miyazaki S. SMA microgripper with integrated antagonism. Sensors Actuators A: Physical. 2000;83(1-3):208-213.

5. Miyazaki S, Kohl M. Recent Development in TiNi-based Shape Memory Alloys. Smart Structures and Materials. 1998; p. 2-13.

6. Fernandes DJ, Elias CN, Vidal R, Mendes AM. Mechanical Performance of Nickel-titanium Archwires. Materials Research. 2015;18(6):1264-1277.

7. Matheus TCU, Lopes HP, Albuquerque DS, Elias CN, Carmo AMR, Otubo J, et al. The fracture evaluation of NiTi SMA endodontics files. Materials Research. 2007;10(4):395-398.

8. Otubo J, Rigo OD, Moura Neto C, Kaufman MJ, Mei PR. Low carbon content NiTi shape memory alloy produced by electron beam melting. Materials Research. 2004;7(2):263-267.

9. Soul H, Yawny A, Lovey FC, Torra V. Thermal effects in a mechanical model for pseudoelastic behavior of NiTi wires. Materials Research. 2007;10(4):387-394.

10. Kumar PK, Lagoudas DC. Introduction to Shape Memory Alloys. In: Lagoudas DC, ed. Shape Memory Alloys. New York: Springer; 2008. p. 1-51.

11. Liu Y, Galvin SP. Criteria for pseudoelasticity in near-equiatomic NiTi shape memory alloys. Acta Materialia. 1997;45(11):44314439 .

12. Wright R. Wire Technology - Process Engineering and Metallurgy. Oxford: Butterworth-Heinemann; 2011. p. 25-26.

13. ASTM International. ASTM F2005-05(2010) - Standard Terminology for Nickel-Titanium Shape Memory Alloys. West Conshohocken: ASTM International; 2010.

14. Wu SK, Lin HC, Yen YC. A study on the wire drawing of TiNi shape memory alloys. Materials Science and Engineering. 1996;215(1-2):113-119.

15. ASTM International. ASTM F2004-16 - Standard Test Method for Transformation Temperature of Nickel-Titanium Alloys by Thermal Analysis. West Conshohocken: ASTM International; 2016.

16. Pelton AR, Dicello J, Miyazaki S. Optimisation of processing and properties of medical grade Nitinol wire. Minimally Invasive Therapy \& Allied Technologies. 2009;9(1):107-118.

17. Kabayama LK, Rigo OD, Otubo J. Influence of Thermomechanical Processing on the Martensitic Transformation Temperatures of NiTi SMA Wire. Materials Science Forum. 2010;643:43-48. 